\begin{tabular}{|c|c|}
\hline $\begin{array}{c}\text { JURJAL } \\
\text { MLWWLEEMEEN } \\
\text { KEWWIRAUSAHLAN }\end{array}$ & $\begin{array}{r}\text { p-ISSN 1858-1048 } \\
\text { e-ISSN 2654-9247 } \\
\text { http://ejurnal.stieipwija.ac.id/index.php/imk } \\
\text { DOI: http://dx.doi.org/10.33370/imk.v16i1.273 } \\
\text { Jurnal Manajemen Kewirausahaan Vol. 16 No. 01 - Juni } 2019 \\
\text { Submit: } 10 \text { Feb 2019; Review: 25 Jun 2019; Publish: 30 Jun } 2019\end{array}$ \\
\hline
\end{tabular}

\title{
PENGARUH SYSTEMIC FAIRNESS TERHADAP CUSTOMER LOYALTY MELALUI TRUST DAN PERVEICED VALUE
}

\author{
Oleh: \\ Sabar Pardamean L. Tobing \\ sabar.trisakti@gmail.com \\ Sekolah Tinggi Ilmu Ekonomi IPWI Jakarta
}

\begin{abstract}
ABSTRAK
Latar belakang dari penelitian ini untuk menjelaskan secara empiris keadilan di dalam menciptakan kepuasan pelanggan yang menggunakan internet pada konteks penggunkaan internet banking. Penelitian ini bertujuan untuk meneliti mekanisme pembentukan keadilan yang menentukan kepuasan pelanggan yang menggunakan internet. Rancangan di dalam penelitian melalui survei digunakan untuk meneliti model penelitian berdasarkan teori hubungan pemasaran yang meneliti keadilan, kepercayaan, nilai yang dirasakan oleh pelanggan, dan kepuasan pelanggan. Total jumlah responden sebanyak 110 responden yang dianalisis menggunakan software AMOS version 7 (Analyses of Moment Structures) melalui teknik Model Persamaan Struktural (SEM). Tujuan dari penelitian ini untuk menjelaskan di dalam penggunaan internet banking, keadilan mencakup keadailan distributif, keadilan prosedural, dan keadilan informasional yang memiliki pengaruh positif terhadap kepuasan pelanggan. Kepercayaan diidentifikasikan sebagai variabel perantara di dalam pembentukan keadilan sehingga tercapainya kepuasaan pelanggan. Hasil dari penelitian ini menyimpulan bahwa pada konteks penggunaan internet, dimana interaksi manusia terjadi dengan teknologi, keadilan berperan penting di dalam menciptakan kepuasan pelanggan. Secara lebih jauh, perbandingan antara konteks penggunaan internet juga dijelaskan. Implikasi menajerial bagi manajer layanan jasa, keadilan penting di dalam pembentukan operasional melibatkan aktivitas pemasaran, konsisten didalam menjalankan prosedur, dan menyampaikan informasi kepada pelanggan. Keterbatasan di dalam penelitian ini merupakan salah satu usaha untuk menjelaskan konsep keadilan di dalam penggunaan internet banking, yang merupakan variabel perantara di dalam menciptakan kepuasan pelanggan yang menggunakan internet.
\end{abstract}

Kata Kunci: internet banking, layanan jasa, perceived value, kepercayaan pelanggan, kepuasan pelanggan

\section{PENDAHULUAN}

Persaingan

memperebutkan nasabah bank di Indonesia sangat ketat. Dengan jumlah bank dan kantor cabang yang masih tetap bnayak dan produk yang ditawarkan bank beragam. Adapun pekembangan teknologi informasi, telekomunikasi, dan internet mendorong para pelaku usaha perbankan mengembangkan pelayanan berbasis internet. Salah satu aplikasi yang menarik perhatian adalah Internet Banking. Dengan internet banking memberikan kemudahan dan kecepatan 
dalam melakukan transaksi perbankan. Loyalitas nasabah adalah strategi yang dilakukan oleh perusahaan bank untuk meningkatkan profitabilitas perusahaan dan perluasan pangsa pasar. Dengan adanya nasabah yang loyal maka dapat menjadi sumber dalam menciptakan keunggulan kompetitif dari perusahaan (Tong, Wong dan Lui 2012).

Dengan adanya loyalitas nasabah maka perusahaan dapat menciptakan retensi pada nasabah dan loyalitas nasabah juga dapat meningkatkan profitabilitas perusahaan. Upaya mencari dan mempertahankan nasabah harus selalu dilakukan bank agar mampu bersaing dengan pesaing lainnya. Ketatnya persaingan dalam dunia perbankan, membuat bank berlombalomba memberikan yang terbaik bagi nasabahnya dengan meluncurkan berbagai jenis produk dan jasa yang lebih unggul dibandingkan dengan yang lain. Untuk meningkatkan loyalitas nasabahnya, perusahaan bank selalu berusaha untuk memberikan kemudahan dalam melakukan transaksi perbankan. Berbagai cara perusahaan bank meningkatkan loyalitas nasabah yang melakukan transaksi internet banking seperti meningkatkan kepercayaan yang dimiliki oleh nasabah dan nilai yang dirasakan oleh pelanggan ketika melakukan transaksi internet banking. Salah satu contohnya adalah penerapan internet banking yang memberikan kemudahan untuk melakukan transaksi dengan tidak langsung datang ke bank, transaksi dapat dilakukan dirumah kapan saja dan tidak perlu membawa uang dalam jumlah besar. Adanya keuntungan yang diberikan perusahaan bank untuk nasabah melakukan transaksi internet banking seperti layanan perbankan 24 Jam, rasa aman, tidak ada biaya bulanan, fitur lengkap, kemudahan akses rekening yang membuat nasabah merasa nyaman dalam bertransaksi. Dengan adanya loyalitas pelanggan dapat meningkatkan profitabilitas dan menciptakan retensi pelangggan (Cheng, Lai dan Yeung 2008).

Untuk memberikan layanan jasa yang terbaik bagi nasabah, pihak bank berusaha agar nasabah merasa bahwa layanan jasa yang diberikan akan sanagat memuaskan nasabahnya agar meningkatkan kepercayaan yang dimiliki oleh nasabah. Untuk mendukung usaha peningkatan loyalitas nasabah maka pihak bank juga berusaha untuk terus mengetahui dan memahami nilai yang paling sesuai dengan karakteristik nasabahnya dan juga faktor-faktor apa yang mampu untuk meningkatkan kepercayaan nasabah.

Untuk meningkatkan kepercayaan yang dimiliki oleh nasabah dalam melakukan transaksi internet banking perusahaan harus dapat selalu adil dalam memberikan pelayanan prima kepada semua nasabah. Perusahaan juga harus selalu adil di dalam memberikan tindakan perbaikan layanan jasa terhadap nasabah yang merasa dirugikan oleh perusahaan penyedia jasa dan perusahaan yang adil berarti mampu memperhatikan hak nasabah.

Beda penelitian sebelumnya adalah adanya penelitian mengenai customer loyalty pada para pengguna internet banking. Seorang nasabah yang loyal dapat menciptakan keinginan mengunjugi website perusahaan bank kembali dimasa yang akan datang (Lee, Jin dan Choi, 2011). Loyalitas nasabah dapat mengurangi biaya untuk mencari nasabah baru dan perusahaan berusaha mempertahankan nasabah yang telah ada karena tidak mengeluarkan banyak biaya dan lebih murah (Tong, Wong dan Lui 2012).

\section{TUJUAN PENELITIAN}

1. Untuk menganalisis pengaruh positif systemic fairness terhadap loyalty.

2. Untuk menganalisis pengaruh positif systemic fairness terhadap trust.

3. Untuk menganalisis pengaruh positif systemic fairness terhadap perceived value.

4. Untuk menganalisis pengaruh positif trust terhadap perveived value.

5. Untuk menganalisis pengaruh trust positif terhadap customer loyalty.

6. Untuk menganalisis pengaruh positif perceived value terhadap customer loyalty. 


\section{TELAAH LITERATUR DAN PENGEMBANGAN HIPOTESIS}

Internet Banking merupalan saah satu cara untuk menciptakan nilai tambah dari produk atau jasa yang dijual oleh perusahaan bank (Redlinghuis dan Rensleigh, 2010). Sentosa, Soebyakto, Ming dan Mat (2012) menemukan adanya penggunaan internet banking sebagai sarana pemasaran di dalam industri keuangan.

Systemic Fairness adalah semua keadilan yang dirasakan oleah pengguna intrnet banking ketika bertransaksi dengan perusahaan (Zhu dan Chen, 2012) Chen dan Chou (2012) memberikan pengertian Systemic Fairness adalah evaluasi yang dilakukan oleh pelanggan dengan membandingkan antara input (apa yang diberikan) dan output (apa yang diterima) dari perusahaan penyedia jasa.

Trus dianggap sebagai suatu perkataan janji, pernyataan verbal atau pernyataan tertulis dari suatu individu pada individu lainnya (Kantsperger dan Kunz, 2010) Trust adalah suatu keyakinan nasabah terhadap perusahaan mengenai kehandalan dan Integritas yang dimiliki perusahaan (Guenzi et al.,2009).

Trus adalah suatu keyakinan yang dimiliki oleh pelanggan terhadap kemampuan yang dimiki oleh perusahaan penyedia jasa dalam meyampaikan produk atau jasa.

\section{Perceived Value}

Anuwichanont dan Mechinda (2009) mendefinisikan Perceived Value adalah suatu penilaian yang dilakukan oleh pelanggan mengenai kegunaan dari suatu produk atau jasa untuk menilai apa yang diterima dan apa yang diberikan oleh perusahaan penyedia jasa. Dapat disimpulan bahwa perceived value adalah suatu penilaian yang dilakukan oleh pelanggan dengan cara membandingkan antara manfaat atau keuntungan yang diterima dengan mengorbankan yang dikeluarkan untuk memperoleh suatu produk atau jasa.

\section{Customer Loyalty}

Gee et all (20080 mengungkapka bahwa loyalitas penting bagi perusahaan yang berusaha untuk mempertahankan para pelanggan. Gee et al (2008) mendefinisikan loyalitas pelanggan sebagai pola dari aktivitas pembelian berikutnya yang dilakukan oleh pelanggan. Jadi Customer Loyalty adalah suatu usaha yang dilakukan perusahaan dalam mempertahankan pelanggan untuk tetap melakukan transaksi pembelian produk atau jasa.

\section{Perumusan Hipotesis}

Keadilan yang diciptakan oleh perusahaan menujukkan bahwa adanya persepsi pelanggan mengenai perilaku pada perusahaan penyedia jasa. Adanya persepsi keadilan yang dimiliki oleh nasabah membuat nasabah berkeinginan untuk berpikir dan merasakan yang terjadi di perusahaan bank sehingga perusahaan bank harus mempertankankan loyalitas nasabah (Lee, Joshi dan Kim, 2011). Persepsi keadilan di dalam menetapkan harga produk atau jasa yang dijual oleh perusahaan penyedia jasa dapat menciptakan loyalitas nasabah (Hu dan Chuang, 2012). Dengan adanya pembentukan loyalitas nasabah maka perusahaan dapat menguasai pangsa pasar (Hsieh dan Kai Li, 2008). Dengan adanya pembentukan loyalitas dari nasabah maka dapat meningkatkan profitabilitas dan pendapatan perusahaan (Castaneda, 2011). Hipotesis dinyatakan sebagai berikut:

H1: Systemic fairness memiliki pengaruh positif terhadap customer loyalty

Keadilan di dalam pemberian potongan harga dan penyampaian produk atau jasa kepada nasabah mampu menciptakan kepercayaan yang dimiliki oleh nasabah terhadap bank (Beattie, 2011).

H2: Systemic fairness memiliki pengaruh positif terhadap trust 
Keadilan yang dirasakan oleh pelanggan berhubungan degan harga dan produk atau jasa yang dijual oleh perusahaan penyedia jasa (Mathies dan Gudergan, 2011).

H3: Systemis fairness memiliki pengaruh positif terhadap perceived value

Kepercayaan timbul karena adanya keyakinan terhadap kemampuan, itikat baik dan integritas yang dimiliki oleh perusahaan penyedia jasa (Chiu, Chang, Cheng, dan Fang, 2009).

H4: Trust memiliki pengaruh positif terhadap perceived value

Dengan adanya kepercayaan maka dapat menciptakan loyalitas nasabah disuatu bank (Deb dan Chavali, 2010).

H5: Trust memiliki pengaruh positif terhadap customer loyalty

Pembentukan nilai pelanggan merupakan strategi yang dilakukan oleh perusahaan untuk menciptakan keunggulan kompetitif dan loyalitas pelanggan (Yee dan Faziharudean, 2010).

H6: Perceived value memiliki pengaruh positif terhadap customer loyalty.

\section{Kerangka Konseptual}

Grabner-Krauter dan Faullant (2008) menemukan bahwa internet banking digunakan oleh perusahaan bank untuk mengimplementasikan bisnis dan nasabah dapat melakukan aktivitas perbankan sehari hari. Perusahaan bank menggunakan internet banking di dalam mempertahankan loyalitas nasabah (Young, Yuan dan Yu, 2012).

Nilai pelanggan menunjukkan adanya persepsi pelanggan mengenai apa yang diterima dibandingkan dengan apa yang diberikan oleh perusahaan penyedia jasa (Anuwichanont dan Mechinda, 2009). Loyalitas pelanggan terbentuk melalui pembentukan keadilan di dalam penyampaian layanan jasa pelanggan (Lee, Joshi dan Kim, 2011). Pesepsi mengenai nilai yang diterima oleh pelanggan menjadi salah satu alasan untuk melakukan transaksi pada suatu perusahaan penyedia jasa (Sabiote et all, 2012). Kepercayaan yang dimiliki oleh nasabah timbul karena adanya keadilan di dalam menjalankan prosedur oleh perusahaan bank (Ling, Daud, Piew, Keoy dan Hassan, 2011). Adapun pengaruh systemic fairness terhadap customer loyalty melalui trust dan perceived value ditunjukkan pada Gambar 1 sebagai berikut.

\section{Gambar 1}

Kerangka/Konstelasi

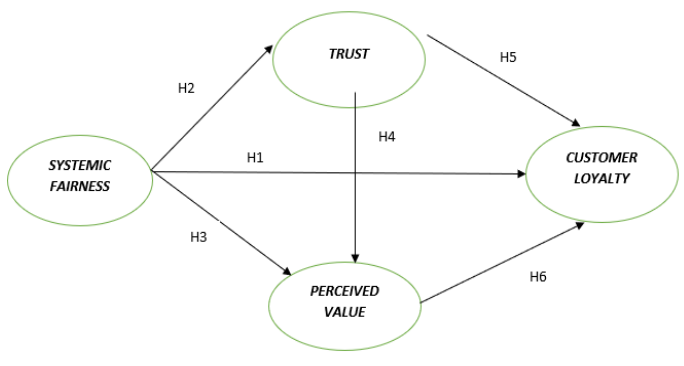

\section{METODE PENELITIAN Sampel Penelitian}

Jumlah sampel dalam penelitian ini dilakukan dengan cara menyebarkan kuesinoer kepada 110 nasabah Bank BNI yang berlokasi di Mutiara Gading, Bekasi Timur. Teknik Pengumpulan sampel yang digunakan adalah metode purposive sampling. Dalam penelitian ini cara penentuan jumlah sampelnya adalah menggunakan rumus Slovian dengan perhitungan sebagai berikut (Hermawan, 2006).

$$
\begin{aligned}
& \mathrm{n}=\frac{\mathrm{N}}{1+\mathrm{N}(e) 2} \\
& \mathrm{n}=\frac{400}{1+400(0,1) 2}=110
\end{aligned}
$$

Dimana:

$\mathrm{N}=$ Jumlah populasi (400 nasabah Bank BNI yang berlokasi di Mutiara Gading, Bekasi Timur)

$\mathrm{e}=$ Error $10 \%$ (Persentase yang dapat ditoleransi terhadap ketidaktepatan penggunaan sampel pengganti populasi)

$\mathrm{n}=$ Jumlah sampel

\section{Desain Penelitian}

Penelitian ini mengacu pada penelitian yang dilakukan oleh $\mathrm{Zhu}$ dan Chen (2012) yang menganalisis pengaruh systemic fairness terhadap loyalty melalui trust dan perceived value. Perbedaan dengan penelitian sebelumnya adalah adanya penelitian mengenai 
customer loyalty pada para pengguna internet banking.

Rancangan penelitian merupakan survey yang bertujuan untuk menguji hipotesis penelitian (hypotheses testing). Daya yang digunakan adalah cross sectional karena data yang dikumpulkan hanya sekali pada suatu periode tertentu dengan unit analisis individu yaitu nasabah Bank BNI yang berlokasi di Mutiara Gading, Bekasi Timur (Hermawan, 2006).

\section{Operasionalisasi Variabel}

Variabel yang digunakan dalam penelitian ini yaitu systemic fairness, trust, perceived value, dan customer loyalty. Adapun pengukuran dari masing-masing variable yang menggunakan beberapa indikator pernyataan sebagai berikut:

\section{Systemic Fairness}

Systemic fairness diadopsi dari penelitian yang dilakukan oleh Zhu dan Chen (2012) diukur dengan skala linkert lima point dimana skala 1 menunjukkan sangat tidak setuju hingga skala 5 menunjukkan sangat setuju yang terdiri dari tiga pernyataan yaitu:

1. Memberikan hasil yang diinginkan untuk semua pengguna internet banking tanpa perbedaan.

2. Menyampaikan hasil yang wajar bagi para pengguna internet banking.

3. Pihak bank konsisten dalam berurusan dengan semua pengguna internet banking.

\section{Trust}

Trust diadopsi dari penelitian yang dilakukan oleh Zhu dan Chen (2012) diukur dengan skala linkert lima point dimana skala 1 menunjukkan sangat tidak setuju hingga skala 5 menunjukkan sangat setuju yang terdiri dari lima pernyataan yaitu:

1. Tidak ada batasan bahwa internet banking dapat memecahkan masalah.

2. Internet banking ini berkomitmen dalam menciptakan kepuasan nasabah.

3. Kebanyakan dari apa yang dikatakan di dalam internet banking mengenai produk besar.
4. Jika internet banking ini membuat pernyataan atau janji mengenai layanan itu benar.

5. Menurut pengalaman nasabah, internet banking ini sangat handal.

\section{Perceived Value}

Perceived value diadopsi dari penelitian yang dilakukan oleh $\mathrm{Zhu}$ dan Chen (2012) diukur dengan skala linkert lima point dimana skala 1 menunjukkan sangat tidak setuju hingga skala 5 menunjukkan sangat setuju yang terdiri dari empat pernyataan yaitu:

1. Layanan internet banking memberikan nilai uang yang baik.

2. Layanan internet banking bernilai baik.

3. Para pengguna senang dengan nilai uang.

4. Jasa yang diberikan sangat bernilai.

\section{Customer Loyalty}

Customer loyalty diadopsi dari penelitian yang dilakukan oleh Casalo, Flavian, dan Guinaliu (2008) diukur dengan skala linkert lima point dimana skala 1 menunjukkan sangat tidak setuju hingga skala 5 menunjukkan sanfat setuju yang terdiri dari dua pernyataan yaitu:

1. Para pengguna internet banking memiliki rencana untuk melanjutkan hubungan.

2. Berdasarkan pada pengalaman yang dimiliki oleh para pengguna internet banking berkeinginan melanjutkan hubungan.

\section{Metode Analisis}

Metode analisis data yang digunakan dengan melihat tujuan penelitian adalah sebagai berikut:

1. Untuk menganalisis systemic fairness, trust, perceived value, dan customer loyalty yang dimiliki oleh nasabah Bank BNI yang berlokasi di Mutiara Gading Bekasi Timur. Metode analisis data yang digunakan adalah analisis statistic deskriptif (rata-rata).

2. Menganalisis pengaruh systemic fairness terhadap customet loyalty melalui trust dan perceived value pada nasabah Bank BNI yang 
berlokasi di Mutiara Gading, Bekasi Timur. Metode analisis data yang digunakan adalah AMOS versi 7 (Analyses of Moment Structures) melalui teknik Structural Equation Model (SEM). Sebelum menganalisis hipotesis penelitian yang diajukan, terlebih dahulu dilakukan pengujian kesesuaian model (goodness of fit model). Pengujian kesesuaian model (goodness of fit model) dilakukan dengan melihat beberapa kriteria pengukuran.

\section{HASIL DAN PEMBAHASAN Hasil Penelitian}

Statistik deskriptif adalah statistic yang menggambarkan fenomena atau karakteristik dari data yang diteliti dalam sistuasi (Sekaran, 2006). Statistik deskriptif adalah suatu deskripsi mengenai pengumpulan, penyusunan, serta penyajian data berdasarkan nilai rata-rata (Mean) (Santoso, 2008). Hasil statistik dari variable-variabel dapat dilihat pada tabel berikut ini:

Tabel 1

Statistik Deskriptif

\begin{tabular}{|c|l|l|l|l|l|}
\hline Varaibel & N & MINUMUM & MAKSIMUM & MEAN & $\begin{array}{l}\text { Std. } \\
\text { DEVIATION }\end{array}$ \\
\hline $\begin{array}{c}\text { Systemic } \\
\text { Fairness }\end{array}$ & 110 & 1,67 & 5,00 & 4,06 & 0,76 \\
\hline Trust & 110 & 1,00 & 5,00 & 3,96 & 0,83 \\
\hline $\begin{array}{l}\text { Perceived } \\
\text { Value }\end{array}$ & 110 & 3,00 & 5,00 & 4,23 & 0,54 \\
\hline $\begin{array}{l}\text { Customer } \\
\text { Loyalty }\end{array}$ & 110 & 2,00 & 5,00 & 4,05 & 0,69 \\
\hline
\end{tabular}

Nilai rata-rata dari pembentukan tanggapan terhadap systemic fairness diperoleh nilai rata-rata sebesar 4,06 maka menunjukkan responden berpendapat bahwa Bank Konsisten dalam berurusan dengan semua pengguna internet banking dengan standar deviasi sebesar 0,76. Nilai ratarata dari pembentukan tanggapan terhadap trust diperoleh nilai rata-rata 3,96 maka menunjukkan responden berpendapat bahwa kebanyakan dari paada yang dikatakan di dalam internet banking mengenai produk benar dengan standar deviasi sebesar 0,83. Nilai ratarata dari pembentukan tanggapan terhadap perceived value diperoleh nilai rata-rata sebesar 4,23 maka menunjukkan responden berpendapat bahwa layanan internet banking bernilai baik dengan standar deviasi sebesar 0,54 . Nilai rata-rata dari pembentukan tanggapan terhadap customer loyalty diperoleh nilai rata-rata sebesar 4,05 maka menunjukkan responden berpendapat bahwa para pengguna internet banking memiliki rencana untuk melanjutkan hubungan dengan standar deviasi sebesar 0,83.

\section{Pengujian Hipotesis 1}

Ho 1: Systemic fairness tidak memiliki pengaruh positif terhadap customer loyalty

Ha1: Systemic fairness memiliki pengaruh positif terhadap customer loyalty

Pada Pengujian hipotesis 1 diketahui p-value $0,008<$ alpha 0,05 dengan nilai beta sebesar 0,331 maka Ho1 ditolak, Ha1 diterima yang artinya Systemic fairness memiliki pengaruh postif terhadap customer loyalty.

\section{Pengujian Hipotesis 2}

Ho2: Systemic fairness tidak memiliki pengaruh positif terhadap trust

Ha2: Systemic fairness memiliki pengaruh positif terhadap trust

Pada Pengujian hipotesis 2 diketahui p-value $0,028<$ alpha 0,05 dengan nilai beta sebesar 0,268 maka Ho2 ditolak, Ha2 diterima yang artinya systemic fairness memiliki pengaruh positif terhadap trust. Dengan adanya pengalaman keadilan secara sistemik yang dirasakan oleh nasabah ketika perusahaan penyedia jasa menyampaikan produk atau jasa dapat menciptakan kepercayaan dari dalam diri nasabah terhadap perusahaan penyedia jasa.

\section{Pengujian Hipotesis 3}

Ho3: Systemic fairness tidak memiliki pengaruh positif terhadap perceived value

Ha3: Systemic faieness memiliki pengaruh positif terhadap perceived value

Pada pengujian hipotesis 3 diketahui p-value $0,001<$ alpha 0,05 dengan nilai beta sebesar 0,238 maka Ho3 ditolak, Ha3 diterima yang artinya systemic fairness memiliki pengaruh positif terhadap perceived value. 


\section{Pengujian Hipotesis 4}

Bunyi hipotesis null (Ho) dan hipotesis alternative $(\mathrm{Ha})$ adalah sebagai berikut:

Ho4: Trust tidak memiliki pengaruh positif terhadap perceived value

Ha4 : Trust memiliki pengaruh positif terhadap perceived value

Pada pengujian hipotesis 4 diketahui p-value 0,017 < alpha0,05 dengan nilai beta sebesar 0,214 maka Ho4 ditolak, Ha4 diterima yang artinya trust meiliki pengaruh postif terhadap perceived value. Dengan adanya kepercayaan yang dimiliki oleh nasabah ketika perusahaan penyedia jasa menyampaikan produk atau jasa dapat menciptakan keinginan nasabah untuk melakukan evaluasi dari manfaat yang diperoleh dari produk atau jasa yang digunakan.

\section{Pengujian Hipotesis 5}

Ho5: Trust tidak memiliki pengaruh positif terhadap customer loyalty

Ha5: Trust memiliki pengaruh positif terhadap customer loyalty

Pada pengujian hipotesis 5 diketahui p-value $0,004<$ alpha 0,05 dengan nilai beta sebesar 0,204 maka Ho5 ditolak, Ha5 diterima yang artinya trust memiliki pengaruh positif terhadap customer loyalty. Dengan adanya keyakinan dari dalam diri nasabah terhadap perusahaan penyedia jasa maka dapat menciptakan rasa setia terhadap produk atau jasa yang ditawarkan oleh penyedia jasa.

\section{Pengujian Hipotesis 6}

Ho6: Perceived value tidak memiliki pengaruh positif terhadap customer loyalty

Ha6: Perceived value memiliki pengaruh positif terhadap customer loyalty

Pada pengujian hipotesis 6 diketahui p-value $0,002<$ alpha 0,05 dengan nilai beta sebesar 0,433 maka Ho6 ditolak, Ha6 diterima yang artinya perceived value memiliki pengaruh positif terhadap customer loyalty. Dengan adanya penilaian terhadap suatu kedalaman komitmen nasabah terhadap perusahaan penyedia jasa, hal ini ditunjukkan dengan adanya internet banking bernilai baik dapat menciptakan pengalaman yang dimiliki oleh para pengguna internet banking. Para pengguna internet banking akan melanjutkan hubungan dengan website ini pada waktu yang akan datang.

\section{KESIMPULAN \\ Simpulan}

Berdasarkan uraian dan analisis yang telah dikemukakan di atas, maka kesimpulan yang diperoleh dari penelitian ini adalah:

1. Systemic fairness berpengaruh postif terhadap customer loyalty diperoleh nilai beta sebesar 0,331.

2. Systemic fairness berpengaruh positif terhadap trust diperoleh nilai beta sebesar 0,238.

3. Systemic fairness berpengaruh positif terhadap perceived value diperoleh nilai beta sebesar 0,238.

4. Trust berpengaruh positif terhadap perceived value diperoleh nilai beta sebesar 0,214.

5. Trust berpengaruh positif terhadap customer loyalty diperoleh nilai beta sebesar 0,204.

6. Perceived Value berpengaruh positif terhadap customer loyalty diperoleh nilai beta 0,433 .

\section{Saran}

Saran yang dapat diberikan untuk penelitian selanjutnya adalah:

1. Saran untuk peneliti selanjutnya dengan memperbaiki kekurangan ataupun keterbatasan yang ada dalam penelitian ini yaitu sebaiknya tidak hanya dilakukan penelitian pada Bank BNI yang berlokasi di Mutiara Gading Bekasi Timur, tetapi dilakukan pada Bank BNI yang berlokasi di wilayah lainnya seperti Bank BNI Cabang Harmoni dan Bank BNI Cabang Fatmawati

2. Saran Penelitian dengan menambah responden nasabah Bank BNI agar penelitian yang dilakukan lebih valid dan akurat serta mewakili jumlah populasi yang ada.

3. Saran untuk penelitian selanjutnya meneliti variable lainnya seperti nationality culture dan service quality. 
DAFTAR PUSTAKA

Alnsour, M.S and Al-Hyra, K. (2011). Internet Banking and Jordanian Corporate Customer: Issue of Security and Trust. Journal of Internet Banking and Commerce, 16(1):1-14.

Bravo, R.Montaner,T., and Pina, M.J. (2009). The Role of Bank Image for Customers Versus Non-Customers. International Journal of Bank Marketing, 27(4):315-334.

Casalo, L.V., Flavian, C. and Guinaliu, M. (2008). The Role of Satisfaction and Website Usability in Developing Customer Loyalty and Positive Word-of-Mounth in the E-Banking Services. The International Journal of Bank Marketing, 26(6):399-417.

Chang, M.H. and Wang, M.W. (2011). The Moderating Effect of Customer Perceived Value on Online Shopping Behavior. Online Information Review, 26(6):399-417.

Chen, H.G.,Liu, J,Y.C., Sheu, T.S., and Yang, M.H. (2012). The Impact of Financial Services Quality and Fairness in Customer Satisfaction. Managing Service Quality, 22(4):399-421.
Edward, M. and Sahadev, S. (2011). Role of Switching Cost in The Service Quality, Perceived Value, Customer Satisfaction and Customer Retention Linkage. Asia Pacific Journal of Marketing and Logistics, 23(3):327-345

Hermawan, A. (2006). Penelitian Bisnis Paradigma Kuantitatif. Jakarta: Grasindo.

Kotler dan Armstrong. (2006). PrinsipPrinsip Pemasaran (Jilid 2). Jakarta: Penerbit Erlangga.

White, A., Breazeale, M., and Collier, J.E. (2012). The Effects of Perceived Fairness on Customer Reponses to Retailer SST Push Policies. Journal of Retailing, 88 (2):250-261.

Zafar, M., Zafar, S., Asif, A. (2012). Service Quality, Customer Satisfaction and Loyalty: An Empirical Analysis of Banking Sector in Pakistan. Information Management and Business Review, 4(3):159-167.

Zhu, Q.Y. and Chen, H.G. (2012). Service Fairness and Customer Satisfaction in Internet Banking: Exploring the Mediating Effects of Trust and Customer Value. Internet Reseach, 22(4):482-498. 